Hospital; Tohoku Labor Welfare Hospital; and the Imaizumi Women's Clinic for the generous supply of materials and acknowledge the technical work of Ms S Endo, Ms V McLachlan, Ms E Oliver, and Ms J Krapez. This study was supported by grants from the National Health and Medical Research Council of Australia. TY is partly supported by the Australia-Japan Foundation.

1 Robertson DM, Foulds LM, Leversha L, et al. Isolation of inhibin from bovine follicular fluid. Biochem Biophys Res Commun 1985;126:220-6.

2 McLachlan RI, Healy DL, Robertson DM, Burger HG, de Kretser DM. The human placenta: a novel source of inhibin. Biochem Biophys Res Commun 1986; 140:485-90.

3 McLachlan RI, Healy DL, Robertson DM, Burger HG, de Kretser DM. Circulating immunoactive inhibin in the luteal phase and early gestation of women undergoing ovulation induction. Fertil Steril 1987;48:1001-5.

4 Petraglia F, Sawchenko P, Lim ATW, Rivier J, Vale W. Localisation, secretion and action of inhibin in human placenta. Science 1987;237:187-9.

\section{Tissue response of gastric mucosa after ingestion of fluoride}

Department of Cariology, School of Dentistry and Departments of Surgery, Anaesthesiology, and Pathology, Karolinska Institute, Huddinge University Hospital, Huddinge, Sweden

Carl-Johan Spak, ODONTDR, associate professor in cariology Svante Siöstedt, MD, associate professor in surgery Lennart Eleborg, MD, associate professor in anaesthesiology

Béla Veress, MD, chief

consultant in morbid anatomy and histopathology

Leif Perbeck, MD, associate professor in surgery

\section{College of Dentistry,} University of Iowa, Iowa, United States

Jan Ekstrand, ODONTDR, professor in caries research

Correspondence to: $\mathrm{Dr} \mathrm{C}-\mathrm{J}$ Spak, ACO AB, Medical Department, Box 1827,

17126 Solna, Sweden.

BrMed f 1989;298:1686-7

\section{Carl-Johan Spak, Svante Sjöstedt, Lennart Eleborg, Béla Veress, Leif Perbeck, Jan Ekstrand}

Fluoride has been used successfully to prevent dental caries and has also been used to treat osteoporosis. Doses of sodium fluoride of about $50 \mathrm{mg}$ a day have long term beneficial effects on the mineral content of bone and the incidence of fracture. ${ }^{\prime}$ These doses, however, have resulted in gastric disturbances in some patients. ${ }^{12}$ We studied the response of the gastric mucosa after a single dose of fluoride.

\section{Methods and results}

Twelve healthy volunteers (age range 22-45, four men and eight women) underwent two endoscopies after overnight fasts. One endoscopy was a control and the other was performed two hours after subjects ingested $20 \mathrm{ml}$ sodium fluoride solution containing $20 \mathrm{mg}$ fluoride $(53 \mathrm{mmol} / \mathrm{l})$. There was at least two weeks between endoscopies to assure complete recovery of the mucosa in case of iatrogenic injuries from the gastroscope. During the endoscopy the mucosa was graded according to an arbitrary scale ( 0 to 4), slightly modified from that of Lanza. ${ }^{3}$ The stomach was also videotaped and the tape later examined by another gastroenterologist. The results of both exami-
Results of macroscopic and microscopic evaluations of gastric mucosa and presence of nausea at control endoscopy and endoscopy after ingestion of $20 \mathrm{mg}$ fluoride

\begin{tabular}{|c|c|c|c|c|c|c|c|c|c|}
\hline \multirow{3}{*}{$\begin{array}{l}\text { Case } \\
\text { No }\end{array}$} & \multicolumn{4}{|c|}{ Macroscopic evaluation ${ }^{\star}$} & \multicolumn{4}{|c|}{ Microscopic evaluation $\nmid$} & \multirow[b]{3}{*}{ Nausea } \\
\hline & \multicolumn{2}{|c|}{ Body of stomach } & \multicolumn{2}{|c|}{ Antrum } & \multicolumn{2}{|c|}{ Body of stomach } & \multicolumn{2}{|c|}{ Antrum } & \\
\hline & Control & Fluoride $\ddagger$ & Control & Fluoride $\neq$ & Control & Fluoride $\neq$ & Control & Fluoride $\ddagger$ & \\
\hline 1 & 1 & 4 & 0 & 4 & 0 & 2 & 0 & 2 & Present \\
\hline 2 & 0 & 4 & 0 & 2 & 0 & 2 & 0 & 2 & \\
\hline 3 & 0 & 4 & 0 & 2 & 0 & 3 & 0 & 2 & Present \\
\hline 4 & 0 & 4 & 0 & 0 & 0 & 2 & 0 & 2 & \\
\hline 5 & 0 & 4 & 0 & 1 & 0 & 2 & 0 & 1 & \\
\hline 6 & 0 & 4 & 0 & 3 & 0 & 1 & 0 & 2 & Present \\
\hline 7 & 0 & 4 & 0 & 0 & 0 & 3 & 0 & 1 & \\
\hline 8 & 0 & 3 & 0 & 0 & 0 & 1 & 0 & 0 & \\
\hline 9 & 0 & 4 & 0 & 0 & 0 & 2 & 0 & 2 & \\
\hline 10 & 0 & 4 & 2 & 0 & 0 & 1 & 0 & 2 & \\
\hline 11 & 0 & 4 & 0 & 2 & 0 & 1 & 0 & 0 & Present \\
\hline 12 & 0 & 4 & 0 & 0 & 0 & 1 & 0 & 1 & \\
\hline
\end{tabular}

Arbitrary scale: $0=$ normal, $1=$ one petechia or erosion, $2=$ two to five, $3=$ six to $10,4=>10$

tArbitrary scale: $0=$ normal, $1=$ either change in surface epithelium with oedema and haemorrhage of stroma or damage to gastric pits, $2=$ damage to both surface epithelium and gastric pits, $3=$ as 2 combined with acute inflammatory cellular response.

$\ddagger=$ Significant difference between fluoride and control according to Wilcoxon's signed rank test, $p<0 \cdot 01$.
5 Mayo KE, Cerelli GM, Spiess J, et al. Inhibin A-subunit cDNAs from porcine ovary and human placenta. Proc Natl Acad Sci USA 1986;83:5849-53.

6 McLachlan RI, Robertson DM, Healy DL, Burger HG, de Kretser DM. Circulating immunoreactive inhibin levels during the normal human menstrual cycle. J Clin Endocrinol Metab 1987;65:954-61.

7 Robertson DM, Tsonis CG, McLachlan RI, et al. Comparison of inhibin immunological and in vitro biological activities in human serum. $\mathcal{F} \mathrm{Clin}$ Endocrinol Metab 1988;67:438-43.

8 Hobson BM. Further observations on the excretion of chorionic gonadotrophin by women with hydatidiform mole. Br f Obstet Gynaecol 1958;65: 253-9.

van Leusden HA. HCG in pathologic pregnancy. Eur 7 Obstet Gynecol Reprod Biol 1973;3:137-46.

10 DuBeshter B, Berkowitz RS, Goldstein DP, Cramer DW, Berstein MR. Metastatic gestational trophoblastic disease; experience at the New England Trophoblastic Disease Center, 1965 to 1985. Obstet Gynecol 1987;69:390-5. 11 Schlaerth JB, Morrow CP, Kletzky OA, Nalick RH, D'Ablaing GA Prognostic characteristics of serum human chorionic gonadotrophin titer regression following molar pregnancy. Obstet Gynecol 1981;58:478-82.

(Accepted 24 April 1989)

were similar ( $\mathrm{p}<0 \cdot 01$, Wilcoxon's signed ran test). Two biopsy specimens were taken from the antrum and two from the body of the stomach The histopathological changes were assessed on an arbitrary scale from 0 to 3 .

After taking fluoride all subjects had petechiae or erosions (graded 3 or 4 ) in the body of the stomach and six had changes (graded 1-4) in the antrum. No petechiae or erosions were recorded in the oesophagus or the duodenum. In four subjects a layer of clotted blood was found over a large part of the gastric mucosa The table shows the results of the macroscopic and microscopic evaluations. Three components of the gastric mucosa were affected by fluoride: the surface epithelium, the gastric pits, and the superficial stroma. The damaged epithelial cells were smaller than undamaged ones, and the vacuoles containing mucus were reduced in size or had disappeared. The most severely damaged epithelium was disrupted or totally lost. The most characteristic changes in the gastric pits were irregular dilatation and flattening of the epithelial cells. There was also a noticeable loss of mucin.

\title{
Comment
}

Our study showed that one ingestion of fluoride at a dose used to treat osteoporosis affects the gastric mucosa. We do not know, however, to what extent repeated doses affect the mucosa, which might adapt after a while, as occurs with regular treatment with aspirin. ${ }^{3}$ Our findings confirm data from experiments on animals, which showed that fairly low concentrations of fluoride can damage the surface of the gastric mucosa. ${ }^{4}$

The low $\mathrm{pH}$ of gastric juice and the formation of hydrogen fluoride probably caused the mucosal injuries. The uncharged molecule can easily penetrate the lipid cell membranes, enter the cell, and dissociate to fluoride and hydrogen ions, which may have toxic effects on enzyme systems and cause structural damage.

Symptoms like nausea and vomiting are not unusual when fluoride is used to treat osteoporosis. ${ }^{2}$ They also occur occasionally when high doses are used for dental prophylaxis. ${ }^{5}$ In our study only four subjects developed nausea, which suggests that using nausea as the first sign of fluoride toxicity might not be valid as all our subjects showed mucosal damage.

Finally, our results are also clinically important in dentistry because as much as 30 mg fluoride may be swallowed by children after prophylactic treatment with fluoride gel ( $1.23 \%$ fluoride). ${ }^{5}$ If the risk of subsequent gastric injury is as high as our results suggest the use of such large amounts of fluoride in children should be questioned.

Part of this study was supported by grants from the Swedish Medical Research Council (No 6002) and the 
National Institute of Dental Research/National Institutes of Health (United States Public Health Services grant No P5O-DE 07010).

1 Mamelle N, Meunier PJ, Dusan R, et al. Risk-benefit ratio of sodium fluoride teatment in primary vertebral osteoporosis. L ancet 1988;ii:361-5.

Riggs BL, Hodgson SF, Hoffman DL, Kelly PJ, Johnson KA, Taves D. Treatment of primary osteoporosis with fluoride and calcium. Clinical tolerance and fracture occurrence. FAMA 1980;243:446-9.

3 Lanza FL. Endoscopic studies of gastric and duodenal injury after the use of ibuprofen, aspirin, and other nonsteroidal anti-inflammatory agents. Am 7 (984:77:19-24.

4 Pashley DH, Allison NB, Easmann RP, McKinney RV, Horner JA, Whitford GM. The effects of fluoride on the gastric mucosa of the rat. $\mathcal{F}$ Oral Pathol 1984;13:535-45.

5 LeComte EJ. Clinical application of topical fluoride products - risks, benefits and recommendations. $\mathcal{F}$ Dent Res 1987;66:1066-71.

(Accepted I March 1989)

\section{Parents' beliefs about vaccination: the continuing propagation of false contraindications}

\author{
Nigel Klein, Kate Morgan, \\ Mark H Wansbrough-Jones
}

\section{Communicable Diseases Unit and Department of Paediatrics, St George's Hospital, London SW17 0QT \\ Nigel Klein, MRCP, senior house officer in communicable diseases \\ Kate Morgan, MRCP, registrar in paediatrics Mark H Wansbrough-Jones, FRCP, consultant physician and senior lecturer in communicable diseases}

Correspondence to: Dr N Klein, Department of Immunology and Infectious Diseases, Institute of Child Health, London WC1N 1EH.

BrMed f 1989;298:1687
Low immunisation rates in England remain a cause for concern. The introduction of the measles, mumps, and rubella vaccine has renewed optimism that the proposed target of $90 \%$ uptake of vaccination could be achieved by $1990,{ }^{1}$ but studies in the early 1980 s suggested that this target is unrealistic. They showed that parents and health care professionals had a poor understanding of the diseases concerned and commonly believed in mythical contraindications to vaccination. Our study aimed to reassess the importance of these obstacles to vaccination.

\section{Subjects, methods, and results}

The study was conducted at this hospital during six weeks from December 1986 to January 1987. Children aged between 3 months and 4 years who were admitted to the communicable diseases unit and two general paediatric wards were entered into the study. Their immunisation history was sought from one or both parents. If the child had not been fully vaccinated at the correct times the parents were asked their reasons for the failure or delay. If they had been advised against vaccination they were asked for the source of advice and the reasons given. We defined the advice given as appropriate or otherwise according to the Department of Health and Social Security's guidelines of 1984.

During the study period 184 children were admitted, of whom $173(94 \%)$ entered the study. A history of immunisation against measles was taken for the

Reasons given by parents for failure to immunise their children. Figures in parentheses are numbers of parents citing true contraindications according to Department of Health and Social Security's guidelines of 1984

\begin{tabular}{|c|c|c|c|c|}
\hline & Pertussis & Measles & Diphtheria, tetanus, and polio & Total \\
\hline \multicolumn{5}{|l|}{ Intercurrent illness: } \\
\hline Febrile & $4(1)$ & 5 & $1(1)$ & \multirow{2}{*}{$18(2)$} \\
\hline Non-febrile & 4 & 3 & 1 & \\
\hline \multicolumn{5}{|l|}{ Allergy: } \\
\hline To egg & 1 & $2(2)$ & & \multirow{2}{*}{17 (2) } \\
\hline Atopy & 7 & 5 & 2 & \\
\hline \multicolumn{5}{|l|}{ Convulsions: } \\
\hline In child & (3) & 2 & & \multirow{3}{*}{$8(5)$} \\
\hline In first degree relative & (2) & 1 & & \\
\hline In second degree relative & 4 & 1 & & \\
\hline \multicolumn{5}{|l|}{ Prematurity: } \\
\hline Handicap & (3) & 1 & \multirow{5}{*}{1} & $5(3)$ \\
\hline No handicap & 3 & & & $3(3)$ \\
\hline Natural infection & 1 & 3 & & 4 \\
\hline Previous reaction to vaccine & (2) & & & \\
\hline Immunosuppression & & (1) & & \\
\hline Apathy and objections & 8 & 18 & 13 & 39 \\
\hline Total & $32(11)$ & $41(3)$ & $18(1)$ & $91(15)$ \\
\hline
\end{tabular}

121 children over 16 months old. No differences were found in any of the study variables between the groups admitted to the communicable diseases unit and the paediatric wards. Uptake of immunisation (diphtheria, tetanus, and polio $89 \%(154 / 173)$; pertussis $64 \%$ (111/173); measles $64 \%(77 / 121)$ ) was similar to national figures ${ }^{2}$ and figures for Wandsworth Health Authority during 1982-6. Altogether 106 children were incompletely vaccinated, and 91 of these had missed vaccinations for inappropriate reasons: in more than a third (39) the reason was parental objection (13) or apathy (26), but two false contraindicationstemporary intercurrent infection and a history of atopy - accounted for a further third. Inappropriate advice was equally likely to have come from general practitioners, health visitors, and health clinics.

\section{Comment}

In the early 1980s several studies examined the reasons for the continuing failure to improve uptake of vaccination. ${ }^{3-5}$ Like those studies, ours highlighted serious deficiencies on the part of health care professionals in explaining and promoting immunisation. Most of the parents (96\%) reported that they had received advice from a health care professional before deciding about their child's vaccination, and in only $28 \%$ of cases was failure to vaccinate the child due to parental inertia. In the remainder it was due to inappropriate advice or parental conviction not refuted by health care professionals. These findings support those of Blair et al, ${ }^{5}$ who concluded that previous consultation with a health care professional did not significantly correlate with a parent's decision on vaccination.

Improving vaccination uptake is important, but we found that many parents, and apparently some doctors and health visitors, still viewed immunisation as a potential hazard that should be avoided if some excuse could be found. Our most important finding was that of all the cases in which the child had missed vaccinations, $38 \%$ could be attributed to either temporary intercurrent infection or atopy. This almost equalled the proportion accounted for by parental apathy and objection (42\%). If these two misunderstandings had been specifically targeted uptake of more than $80 \%$ might have been achieved.

Much hope is being invested in the new measles, mumps, and rubella vaccine, but the obstacles to full vaccination highlighted in our study clearly reflect deeply entrenched attitudes. A more directed and sustained effort will be needed to change these if we are to improve uptake of vaccination.

\footnotetext{
Begg NT, Noah ND. Immunisation targets in Europe and Britain. Br Med $\mathcal{f}$ 1985;291:1370.

2 Central Statistical Office. Social trends 18. London: HMSO, 1988:123.

3 Nicoll A. Contraindications to whooping cough immunisation-myths or realities. Lancet 1985;i:679-81.

4 Campbell AGM. Measles immunisation: why have we failed? Arch Dis Child 1983;58:3-5. 5 Blair S, Shave N, McKay J. Measles matters, but do parents know? Br Med $\mathcal{F}$
1985;290:623-4.
} 